\title{
Precise determination of the motion of planets and some astronomical constants from modern observations
}

\author{
E. V. Pitjeva \\ Institute of Applied Astronomy, Russian Academy of Science, 10, Kutuzova emb., \\ St. Petersburg, 191187, Russia \\ email: evp@quasar.ipa.nw.ru
}

\begin{abstract}
The accomplishments of space flights and introduction of new astrometric methods (radar ranging, lunar laser-ranging, VLBI measurements) in the 1960s required considerably more precise planetary ephemerides than it was possible with classical analytical theories by Leverrier, Hill, Newcomb and Clemence. On the other hand, these modern data made possible the creation of such ephemerides. Two series of numerical ephemerides of planets most complete up to now, and of the same level of accuracy, are considered in this paper. There are the well-known numerical DE ephemerides of JPL as well as the EPM (Ephemerides of Planets and the Moon) ephemerides produced at the Institute of Applied Astronomy. The description of the dynamical models, the brief characteristics of DE118, DE200, DE403, DE405, DE410, EPM87, EPM98, EPM2000, EPM2004 ephemerides, and the comparison between DE410 and EPM2004 are given. The latest DE410 and EPM2004 ephemerides have resulted from a least squares adjustment to observational data totaling about 300000 position observations (19112003) of different types. The accurate radar observations of planets and spacecraft have made it possible not only to improve the orbital elements of planets but to determine a broad set of astronomical constants from the value of the astronomical unit (AU) to parameters of PPN formalism. Recent estimates of different astronomical constant are presented, and progress is shown in the improvement of the $\mathrm{AU}$ value, the parameters $\beta, \gamma$, as well as possible variability of the gravitational constant $G$.
\end{abstract}

\section{Dynamical models of planetary motion of DE and EPM ephemerides}

Until the 1960s, classical analytical theories of planets (Leverrier, Hill, Newcomb, Clemence) were constantly being improved in order to meet practical needs. The accomplishment of space flights and introduction of new astrometric methods (radar ranging, lunar laser-ranging, VLBI measurements) required considerably more precise planetary ephemerides than those possible with classical theories. On the other hand, these modern data made possible the creation of such ephemerides.

Currently, the creation of these ephemerides is an easier process by using numerical integration of the equations of the motion of the planets and the Moon. At the same time, to ensure space flights the construction of numerical planetary ephemerides was undertaken by several groups in the USA and Russia. Two dynamical models of planet motion having the same level of accuracy, and being most complete up to now are considered in this paper. They are the well-known numerical DE ephemerides of JPL and the EPM (Ephemerides of Planets and the Moon) ephemerides produced at the Institute of Applied Astronomy. 
As for analytical ephemerides of planets, the most precise analytical theories of planets and the Moon are the series of French ephemerides VSOP (Bretagnon \& Francou 1988) and ELP (Chapront \& Chapront-Touzé 1987), produced in BDL and IMCCE. Recently, significant progress has been achieved for the new analytical ephemeris VSOP2002b (Fienga \& Simon 2004), where perturbations from the Moon, the 300 main belt asteroids, the solar oblateness and relativistic corrections have been accounted for. However, a comparison of this ephemeris with numerical ephemerides which began to be constructed in IMCCE shows differences between them up to $100 \mathrm{~m}$ over three decades. Furthermore, the values of the initial conditions of these ephemerides were obtained by fitting to DE200, DE403, DE405 rather than by fitting to the observation data.

Common to all DE and EPM ephemerides is a simultaneous numerical integration of the equations of motion of the nine major planets, the Sun, the Moon and the lunar physical libration performed in the Parameterized Post-Newtonian metric for the harmonic coordinates $\alpha=0$ and General Relativity values $\beta=\gamma=1$.

The various ephemerides differ slightly in

- the modeling of the lunar libration,

- the reference frames,

- the accepted value of the solar oblateness,

- the modeling of the perturbations of asteroids upon the planetary orbits,

- the sets of observations to which ephemerides are adjusted.

Some characteristics of DE118, DE200, DE403, DE405, DE410, EPM87, EPM98, EPM2000, EPM2004 ephemerides are given in Table 1.

Earlier ephemerides have been aligned onto the FK4 reference frame, then onto the dynamical equator and equinox and now ephemerides are oriented onto the International Celestial Reference Frame (ICRF) by including in the adjustment the ICRF-based VLBI measurements of spacecraft near to planets.

The solar oblateness causes a secular trend in the planetary elements except for the semi-major axis and eccentricity (for example, see Brumberg 1972). Starting with DE405 (Standish 1998) a nonzero value of the solar oblateness $J_{2}=2 \cdot 10^{-7}$ obtained from some astrophysical estimates was accepted for integrating of DE and EPM ephemerides. Now the value of the solar oblateness is determined while processing the observations.

A serious problem in the construction of planetary ephemerides arises due to the necessity to take into account the perturbations caused by minor planets. In DE200 (Standish 1990) and our previous versions, the perturbations from only three or five biggest asteroids were accounted for. The experiment showed that the fitting of these ephemerides to the Viking lander data is poor. The perturbations from 300 asteroids were taken into account in the ephemerides starting with DE403 (Standish et al. 1995), and EPM98 (Pitjeva 2001) ephemerides. EPM2000 and EPM2004 have been produced by simultaneous numerical integrations of equations of motion of all planets and the 300 main belt asteroids, therefore the perturbations of these asteroids are accounted for all planets. However, masses of many of these asteroids are quite poorly known, and as shown by Standish \& Fienga (2002), the accuracy of the planetary ephemerides deteriorates due to this factor. Masses of few most massive asteroids which more strongly affect Mars and the Earth can be estimated from observations of martian landers and spacecraft orbiting Mars. The five of 300 asteroids proved to be double and their masses are known now. The masses of Eros (433) and Mathilda (253) have been derived by perturbations of the spacecraft during the NEAR flyby. Unfortunately, the classical method of determining masses of asteroids for which close encounters occur is limited by uncertainty in masses of the large asteroids, perturbations by others, unmodeled asteroids, and the quality of observations. Perhaps masses of many asteroids will be obtained by high accuracy observations during 
Table 1. Ephemerides DE and EPM

\begin{tabular}{|c|c|c|c|c|c|c|}
\hline ephemeris & $\begin{array}{l}\text { interval of } \\
\text { integration }\end{array}$ & $\begin{array}{l}\text { ref. } \\
\text { frame }\end{array}$ & $\begin{array}{l}\text { mathematical } \\
\text { model }\end{array}$ & type & $\begin{array}{r}\text { data } \\
\text { number }\end{array}$ & interval \\
\hline $\begin{array}{c}\text { DE118 } \\
(1981) \\
\Downarrow \\
\text { DE200 }\end{array}$ & $1599 \rightarrow 2169$ & $\begin{array}{c}\text { FK4 } \\
\Downarrow \\
\Downarrow \\
\text { dynamic. } \\
\text { frame }\end{array}$ & $\begin{array}{l}\text { Integrating of } \\
\text { Sun,Moon, } 9 \text { planets } \\
+ \text { perturbations } \\
\text { from } 3 \text { asteroids } \\
\text { (Keplerian ellipses) }\end{array}$ & $\begin{array}{l}\text { optical } \\
\text { radar } \\
\text { spacecraft } \\
\text { LLR } \\
\text { total }\end{array}$ & $\begin{array}{r}44755 \\
1307 \\
1408 \\
2954 \\
50424\end{array}$ & $\begin{array}{l}1911-1979 \\
1964-1977 \\
1971-1980 \\
1970-1980 \\
1911-1980\end{array}$ \\
\hline $\begin{array}{c}\text { EPM87 } \\
(1987)\end{array}$ & $1700 \rightarrow 2020$ & FK4 & $\begin{array}{l}\text { Integrating of } \\
\text { Sun,Moon,9 planets } \\
\text { +perturbations } \\
\text { from } 5 \text { asteroids } \\
\text { (Keplerian ellipses) }\end{array}$ & $\begin{array}{l}\text { optical } \\
\text { radar } \\
\text { spacecraft } \\
\text { LLR } \\
\text { total }\end{array}$ & $\begin{array}{r}48709 \\
5344 \\
\mathrm{t} \quad \\
1855 \\
55908\end{array}$ & $\begin{array}{c}1717-1980 \\
1961-1986 \\
- \\
1972-1980 \\
1717-1986\end{array}$ \\
\hline $\begin{array}{c}\text { DE403 } \\
(1995) \\
\Downarrow \\
\text { DE404 }\end{array}$ & $\begin{array}{c}-1410 \rightarrow 3000 \\
\Downarrow \\
-3000 \rightarrow 3000\end{array}$ & ICRF & $\begin{array}{l}\text { Integrating of } \\
\text { Sun,Moon, } 9 \text { planets } \\
\text { + perturbations } \\
\text { from } 300 \text { asteroids } \\
\text { (mean elements) }\end{array}$ & $\begin{array}{l}\text { optical } \\
\text { radar } \\
\text { spacecraft } \\
\text { LLR } \\
\text { total }\end{array}$ & $\begin{array}{r}26209 \\
1341 \\
1935 \\
9555 \\
39057\end{array}$ & $\begin{array}{l}1911-1995 \\
1964-1993 \\
1971-1994 \\
1970-1995 \\
1911-1995\end{array}$ \\
\hline $\begin{array}{c}\text { EPM98 } \\
(1998)\end{array}$ & $1886 \rightarrow 2006$ & DE403 & $\begin{array}{l}\text { Integrating of } \\
\text { Sun,Moon,9 planets } \\
5 \text { aster.+ perturb. } \\
\text { from } 295 \text { asteroids } \\
\text { (mean elements) }\end{array}$ & $\begin{array}{l}\text { optical } \\
\text { radar } \\
\text { spacecraft } \\
\text { LLR } \\
\text { total }\end{array}$ & $\begin{array}{r}- \\
55959 \\
1927 \\
10000 \\
67886\end{array}$ & $\begin{array}{c}- \\
1961-1995 \\
1971-1982 \\
1970-1995 \\
1961-1995\end{array}$ \\
\hline $\begin{array}{c}\text { DE405 } \\
(1997) \\
\Downarrow \\
\text { DE406 }\end{array}$ & $-3000 \rightarrow 3000$ & ICRF & $\begin{array}{l}\text { Integrating of } \\
\text { Sun,Moon, } 9 \text { planets } \\
\text { + perturbations } \\
\text { from } 300 \text { asteroids } \\
\text { (integrated) }\end{array}$ & $\begin{array}{l}\text { optical } \\
\text { radar } \\
\text { spacecraft } \\
\text { LLR } \\
\text { total }\end{array}$ & $\begin{array}{r}28261 \\
955 \\
1956 \\
11218 \\
42410\end{array}$ & $\begin{array}{l}1911-1996 \\
1964-1993 \\
1971-1995 \\
1969-1996 \\
1911-1996\end{array}$ \\
\hline $\begin{array}{l}\text { EPM2000 } \\
(2000)\end{array}$ & $1886 \rightarrow 2011$ & DE405 & $\begin{array}{l}\text { Integrating of } \\
\text { Sun,Moon, } \\
9 \text { planets, } \\
300 \text { asteroids }\end{array}$ & $\begin{array}{l}\text { optical } \\
\text { radar } \\
\text { spacecraft } \\
\text { LLR } \\
\text { total }\end{array}$ & $\begin{array}{r}- \\
58076 \\
\mathrm{t} \\
24587 \\
13500 \\
96163\end{array}$ & $\begin{array}{c}- \\
1961-1997 \\
1971-1997 \\
1970-1999 \\
1961-1999\end{array}$ \\
\hline $\begin{array}{l}\text { DE410 } \\
(2003)\end{array}$ & $1901 \rightarrow 2019$ & ICRF & $\begin{array}{l}\text { Integrating of } \\
\text { Sun,Moon,9 planets } \\
\text { + perturbations } \\
300 \text { ast.integrated }\end{array}$ & $\begin{array}{l}\text { optical } \\
\text { radar } \\
\text { spacecraft } \\
\text { LLR } \\
\text { total }\end{array}$ & $\begin{array}{r}39159 \\
978 \\
\mathrm{t} 154685 \\
9555 \\
204377\end{array}$ & $\begin{array}{l}1911-2003 \\
1964-1997 \\
1971-2003 \\
1970-1995 \\
1911-2003\end{array}$ \\
\hline $\begin{array}{l}\text { EPM2004 } \\
(2004)\end{array}$ & $1886 \rightarrow 2011$ & ICRF & $\begin{array}{l}\text { Integrating of } \\
\text { Sun,Moon, } \\
9 \text { planets, } \\
301 \text { asteroids, } \\
\text { asteroid ring }\end{array}$ & $\begin{array}{l}\text { optical } \\
\text { radar } \\
\text { spacecraft } \\
\text { LLR } \\
\text { total }\end{array}$ & $\begin{array}{r}46064 \\
58116 \\
\mathrm{t} 197271 \\
15590 \\
317041\end{array}$ & $\begin{array}{l}1913-2003 \\
1961-1997 \\
1971-2003 \\
1970-2003 \\
1913-2003\end{array}$ \\
\hline
\end{tabular}

the Gaia mission, but it will not be soon. So at present masses of the rest of the 301 asteroids have been estimated by the astrophysical method. The latest published diameters of asteroids based on infrared data of IRAS (Infra Red Astronomical Satellite) and MSX (Midcourse Space Experiment), as well as observations of occultations of stars by minor planets and radar observations have been used in this paper. The mean densities for $\mathrm{C}, \mathrm{S}, \mathrm{M}$ taxonomy classes have been estimated while processing the observations. 
At the several meters level of accuracy the orbit of Mars is very sensitive to perturbations from many minor planets. These objects are mostly too small to be observed from the Earth, but their total mass is large enough to affect the orbits of the major planets. The main part of these celestial bodies moves in the asteroid belt and their instantaneous positions may be considered homogeneously distributed along the belt. Thus, it seems reasonable to model the perturbations from the remaining small asteroids (for which individual perturbations are not accounted for) by computing additional perturbations from a massive ring with the constant mass distribution in the ecliptic plane (Krasinsky et al. 2002). Two parameters that characterize the ring (its mass and radius) are included in the set of solution parameters for EPM2004.

The quality of ephemerides, i.e. their accuracy, mostly depends upon improvement of quality and increase of amount of observational data. The section below maintains the description of the database of modern ephemerides. However, we should stress here the uniqueness of the EPM87 ephemeris (Krasinsky et al. 1993), whose parameters were fit to a large variety of observational data for the time span of XVIII-XX centuries, including observations of 32 transits of Mercury (1723-1973) and 4 transits of Venus (1761-1881) across the solar disc, used in order to correct the adopted Brouver system of differences between ET and UT back into the past till 1715, to estimate variations of the solar radius, the Mercury perihelion and node advance.

Along with the planetary ephemerides the ephemerides of the orbital and rotational motions of the Moon were being produced and improved on by processing LLR observations at JPL and IAA RAS. The last versions of the lunar theory of the JPL are given in Williams \& Dickey (2002) and of the IAA — in Krasinsky 2002 where a number of subtle selenodynamical effects is described.

The lunar-planetary integrator for EPM is embedded into the program package (Krasinsky \& Vasilyev 1997) ERA-7 (ERA: Ephemeris Research in Astronomy) developed to support scientific research in dynamical and ephemeris astronomy. Integrating and other computations have been done by using this package.

\section{Processing radar and optical data}

Since the creation of DE405 in 1997, the quality and quantity of observational data have vastly improved. New high accuracy observations have evolved: ranging and Doppler measurements from the martian lander Pathfinder, range and VLBI points from MGS and Odyssey, CCD astrometric data of the outer planets and their satellites. So, the latest DE410 and EPM2004 ephemerides have resulted from a least squares adjustment to the observational data totaling about 300000 position observations (1911-2003) of different types. Data used for the production of the EPM2004 ephemeris were taken from databases of the JPL website (http:/ssd.jpl.nasa.gov/iau-comm4/) created and kept by Dr. Standish, the database of optical observations of Dr. Sveshnikov and extended to include Russian radar observations of planets (on the website of IAA http: //www.ipa.nw.ru/ PAGE/DEPFUND/LEA/ENG/englea.htm). All the observations used are described in Tables 2 and 3 .

The reduction of the radar measurements maintains all the relevant corrections, including the modeling of Mercury, Venus and Mars topography. However, uncertainties due to planetary topography do remain in radar ranging despite the modeling of topography. So, observations of the martian Viking, Pathfinder landers, MGS and Odyssey data which are free from these uncertainties are of great importance.

Unfortunately, observations of MGS and Odyssey as distinct from two frequencies measurements of Viking were carried out at one frequency and the effect of the solar corona delay was considerable, particularly near superior solar conjunctions in 1998 and 
Table 2. Radiometric observations used in the ephemeris solutions. MERCURY

\begin{tabular}{|c|c|c|c|c|c|}
\hline $\begin{array}{l}\text { station, } \\
\text { object }\end{array}$ & type & $\begin{array}{l}\text { time } \\
\text { interval }\end{array}$ & $\begin{array}{l}\text { number } \\
\text { of obs. }\end{array}$ & $\begin{array}{r}\text { normal } \\
\text { points }\end{array}$ & $\begin{array}{l}\text { a priori } \\
\text { accuracy }\end{array}$ \\
\hline Millstone & $\tau$ & 1964 & 5 & - & $7.5-75 \mathrm{~km}$ \\
\hline Haystack & $\tau$ & $1966-1971$ & 217 & - & $3 \mathrm{~km}$ \\
\hline Arecibo & $\tau$ & $1964-1982$ & 341 & 323 & $3-30 \mathrm{~km}$ \\
\hline Goldstone & $\tau$ & $1971-1997$ & 259 & 138 & $1.5-3 \mathrm{~km}$ \\
\hline Goldstone cl.p. & $\tau$ & 1990-1997 & 40 & - & $0.15-2.5 \mathrm{~km}$ \\
\hline Crimea & $\tau$ & 1980-1995 & 75 & 23 & $1.2-4.8 \mathrm{~km}$ \\
\hline \multirow[t]{2}{*}{ Mariner-10 } & $\tau$ & $1974-1975$ & 一 & 2 & $0.1 \mathrm{~km}$ \\
\hline & & VENUS & & & \\
\hline Millstone & $\tau$ & $1961-1967$ & 135 & - & $1.5-120 \mathrm{~km}$ \\
\hline Haystack & $\tau$ & $1966-1971$ & 219 & - & $1.5 \mathrm{~km}$ \\
\hline Arecibo & $\tau$ & $1964-1970$ & 319 & - & $3-15 \mathrm{~km}$ \\
\hline Goldstone & $\tau$ & 1964-1990 & 512 & - & $1.5-6 \mathrm{~km}$ \\
\hline Crimea & $\tau$ & $1962-1995$ & 1139 & 170 & $0.15-22.5 \mathrm{~km}$ \\
\hline \multirow[t]{2}{*}{ Magellan } & $\alpha \delta$ & 1990-1994 & 一 & 18 & $0 . .001-0 . .004$ \\
\hline & & MARS & & & \\
\hline Haystack & $\tau$ & $1967-1973$ & 3801 & 133 & $0.075-12 \mathrm{~km}$ \\
\hline Arecibo & $\tau$ & 1965-1973 & 1680 & 43 & $0.075-45 \mathrm{~km}$ \\
\hline Goldstone & $\tau$ & 1969-1994 & 48989 & 149 & $0.075-0.6 \mathrm{~km}$ \\
\hline Crimea & $\tau$ & 1971-1995 & 381 & 78 & $0.15-4.8 \mathrm{~km}$ \\
\hline Mariner-9 & $\tau$ & $1971-1972$ & 643 & - & $15-270 \mathrm{~m}$ \\
\hline Viking-1 & $\tau$ & $1976-1982$ & 1161 & - & $7-12 \mathrm{~m}$ \\
\hline Viking-1 & $d \tau$ & $1976-1978$ & 14980 & - & $0.16-3.2 \mathrm{~m}$ \\
\hline Viking-2 & $\tau$ & $1976-1977$ & 80 & - & $7-10 \mathrm{~m}$ \\
\hline Pathfinder & $\tau$ & 1997 & 90 & - & $10-22 \mathrm{~m}$ \\
\hline Pathfinder & $d \tau$ & 1997 & 7576 & - & $0.012 \mathrm{~m}$ \\
\hline Phobos & $\tau$ & 1989 & - & 1 & $0.2 \mathrm{~km}$ \\
\hline MGS & $\tau$ & 1998-2003 & 110538 & 4930 & $2-7.5 \mathrm{~m}$ \\
\hline Odyssey & $\tau$ & $2002-2003$ & 62093 & 1715 & $2-3 \mathrm{~m}$ \\
\hline \multirow[t]{2}{*}{ spacecraft } & $\alpha \delta$ & $1984-2003$ & - & 44 & $0 . .0003-0 .{ }^{\prime \prime} 006$ \\
\hline & & JUPITER & & & \\
\hline spacecraft, VLA & $\alpha$ & 1979-1995 & 一 & 4 & $0.003-0 .{ }^{\prime \prime} 046$ \\
\hline spacecraft, VLA & $\delta$ & 1979-1995 & - & 4 & $0.005-0 .{ }^{\prime \prime} 2$ \\
\hline spacecraft & $\tau$ & 1973-1995 & - & 6 & $1-6 \mathrm{~km}$ \\
\hline spacecraft & $\alpha \delta$ & 1996-1997 & - & 24 & $0 . .007-0 .{ }^{\prime \prime} 012$ \\
\hline Arecibo s 3,4 & $\tau$ & 1992 & - & 4 & $3-14 \mathrm{~km}$ \\
\hline
\end{tabular}

2002. The following model was used for the solar corona reduction:

$$
N_{e}(r)=\frac{A}{r^{6}}+\frac{B+\dot{B} t}{r^{2}}
$$

where $N_{e}(r)$ is the electron density.

The parameters $B$ and $\dot{B}$ determined from observations were different for different solar conjunctions. Although residuals decreased considerably, remaining influence of the 
corona has been seen in them (see rms of MGS and Odyssey in Fig. 3). Moreover, the parameters of the corona are correlated with other estimated parameters of the Mars orbit and deteriorate their determination. This fact should be taking into account for highly precise astrometrical measurements of future space missions.

The residuals of all radiometric data are shown in Figs 1-3. The rms residuals of ranging for the Mercury are $1.4 \mathrm{~km}$, for Venus and Mars are $0.7 \mathrm{~km}$, for Viking are $8 \mathrm{~m}$, for Pathfinder $4.4 \mathrm{~m}$, for MGS and Odyssey $1.4 \mathrm{~m}$. The estimations of biases due to uncertainties of the calibration for Viking ranges (about $20 \mathrm{~m}$ ) and for Odyssey ranges (about $2 \mathrm{~m}$ ) have been obtained from the observations the way it has been done for the DE410 ephemeris.
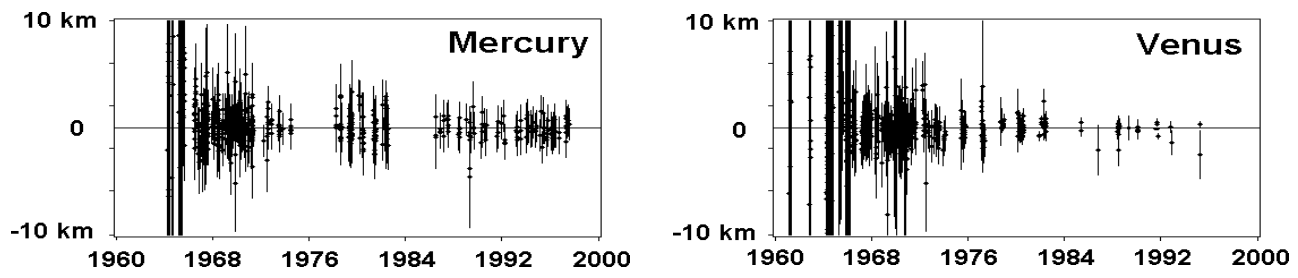

Figure 1. Ranging residuals for Mercury and Venus.
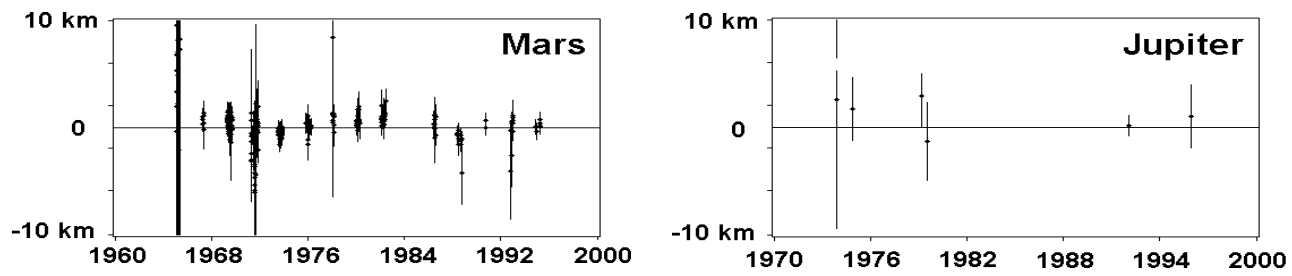

Figure 2. Ranging residuals for Mars and Jupiter.
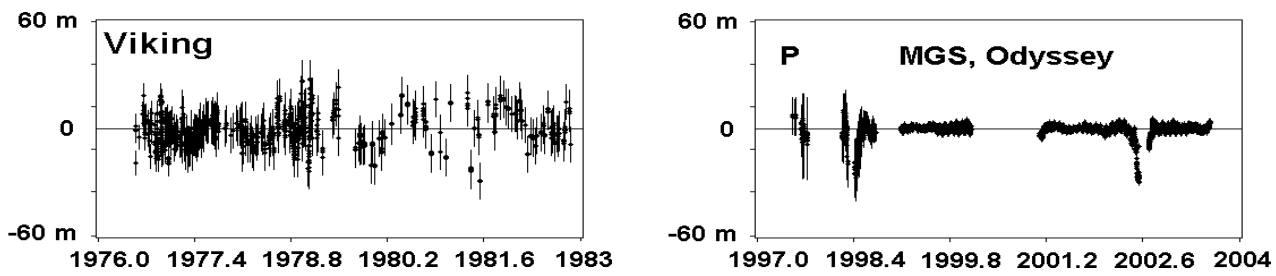

Figure 3. Ranging residuals of Viking, Pathfinder-P (1997), MGS (1998-2003), Odyssey (2002-2003).

The observations of satellites of Jupiter and Saturn are of great importance for optics, as they are more accurate than the observations of their parent planets and practically free from the phase effect. CCD data, obtained at Flagstaff observatory, whose observational program started in 1995 and is still being continued are the most accurate. Another group of high accuracy data is photographic observations of satellites of Jupiter, Saturn, as well as Uranus and Neptune planets obtained at Nikolaev observatory during 19621998. Combination of the data from Flagstaff and Nikolaev has been successfully used to improve the planet ephemerides. Residuals of all the observations of the outer planets are shown in Fig. 4. Unfortunately, observations of Pluto are mainly photographic and of quite poor accuracy, so their rms residuals are worse. 

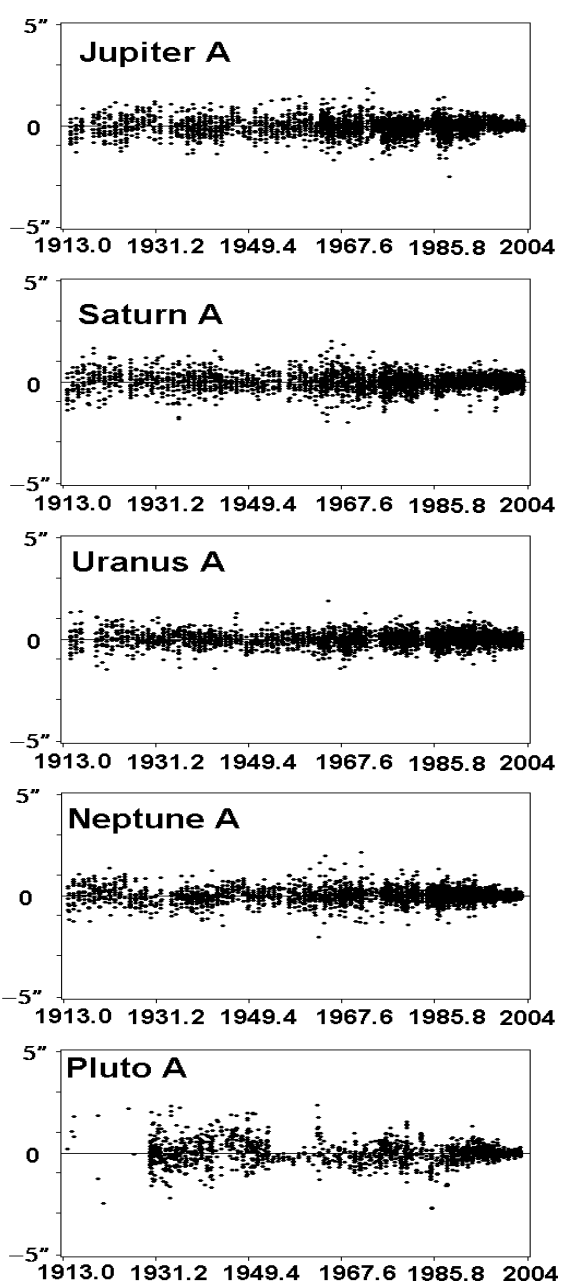
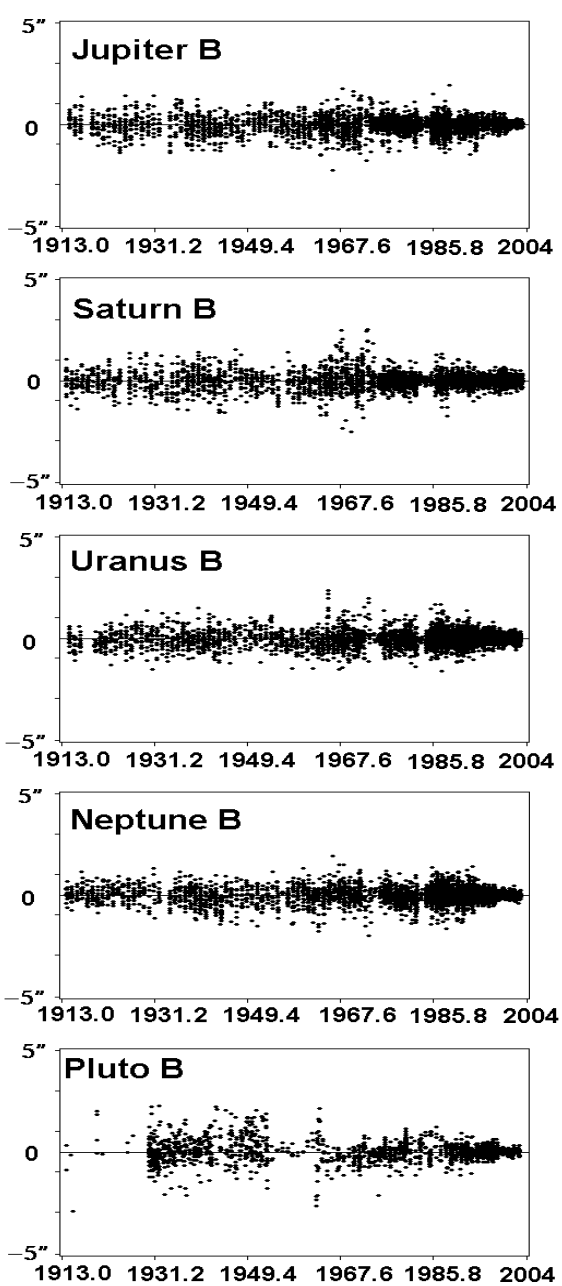

Figure 4. Residuals of the outer planets $1913-2003$ in $\alpha \cos \delta(\mathrm{A})$ and in $\delta(\mathrm{B})$, the scale $\pm 5^{\prime \prime}$.

Ephemerides EPM were oriented onto the International Celestial Reference Frame (ICRF). The most precise optical data of the outer planets and their satellites, obtained at Flagstaff, Nikolaev, La Palma have already been referenced to the ICRF. The remaining optical observations, referenced to different catalogues, at first were transformed to the FK4 systems by Sveshnikov. Then they were referenced to the FK5 using known formulae (see as the example Standish et al. 1995), and were finally transformed to the ICRF using the values of the three angles of the rotation between the HIPPARCOS and FK5 catalogues, J2000 in mas (Mignard 2000):

$$
\varepsilon_{x}=-19.9, \varepsilon_{y}=-9.1, \varepsilon_{z}=22.9 .
$$

Orbits of the four inner planets (with the exception of angles of the orientation) are determined entirely by the ranging observations of planets and spacecraft. The orientation of this system is provided by the using the ICRF-base VLBI measurements of spacecraft. The orientation has been improved considerably due to an addition to previous Magellan and Phobos data of new VLBI points of MGS and Odyssey. The angles of the rotation 
Table 3. Optical and radio observations used in the ephemeris solutions of the outer planets. JUPITER

\begin{tabular}{|c|c|c|c|c|c|}
\hline $\begin{array}{l}\text { station, } \\
\text { object }\end{array}$ & $\begin{array}{l}\text { planet } \\
\text { satellite }\end{array}$ & type & $\begin{array}{c}\text { time } \\
\text { interval }\end{array}$ & $\begin{array}{l}\text { number } \\
\text { of obs. }\end{array}$ & $\begin{array}{l}\text { a priori } \\
\text { accuracy }\end{array}$ \\
\hline USNO & $\mathrm{p}$ & transit & 1913-1994 & 4388 & $0 . .5$ \\
\hline Tokyo & $\mathrm{p}$ & ph-e transit & $1963-1988$ & 568 & $0 .{ }^{\prime \prime} 5-0 .{ }^{\prime \prime} 8$ \\
\hline La Palma & s 3,4 & ph-e transit & 1986-1997 & 1316 & 0.25 \\
\hline Nikolaev & s $1,2,3,4$ & photo & $1962-1998$ & 2628 & $0 .{ }^{\prime \prime} 2$ \\
\hline Flagstaff & s $1,2,3,4$ & CCD & $1998-2003$ & 2408 & $0 .{ }^{\prime \prime} 2$ \\
\hline Mountain & s $1,2,3,4$ & CCD & 2002-2002 & 16 & 0.15 \\
\hline \multicolumn{6}{|c|}{ SATURN } \\
\hline USNO & $\mathrm{p}$ & transit & 1913-1982 & 3054 & $0 .{ }^{\prime \prime} 5$ \\
\hline Tokyo & $\mathrm{p}$ & ph-e transit & 1963-1988 & 506 & $0 .{ }^{\prime \prime} 5-0 .{ }^{\prime \prime} 8$ \\
\hline Bordeaux & s 6,8 & ph-e transit & 1987-1993 & 238 & 0.25 \\
\hline La Palma & s $5,6,7,8$ & ph-e transit & $1987-1997$ & 1460 & $0 . ' 25$ \\
\hline Nikolaev & s $3,4,5,6,8$ & photo & 1973-1997 & 1264 & $0 . .2$ \\
\hline Flagstaff & s $3,4,5,6,7,8$ & $\mathrm{CCD}$ & 1998-2003 & 4014 & 0.2 \\
\hline Mountain & s $3,4,5,6,7,8$ & CCD & $2002-2003$ & 628 & 0.15 \\
\hline VLA & $\mathrm{p}$ & radio & 1984 & 8 & $0 .{ }^{\prime \prime} 03-0$. \\
\hline \multicolumn{6}{|c|}{ URANUS } \\
\hline USNO & $\mathrm{p}$ & transit & 1913-1993 & 4244 & $0 .{ }^{\prime \prime} 5$ \\
\hline Tokyo & $\mathrm{p}$ & ph-e transit & 1963-1988 & 366 & $0 . .5-0 .{ }^{\prime \prime} 8$ \\
\hline Bordeaux & $\mathrm{p}$ & ph-e transit & 1985-1992 & 330 & $0 . \prime 25$ \\
\hline Bordeaux & $\mathrm{p}$ & $\mathrm{CCD}$ & 1997 & 34 & $0 .{ }^{\prime \prime} 2$ \\
\hline La Palma & $\mathrm{p}, \mathrm{s} 4$ & ph-e transit & $1984-1997$ & 2072 & $0 .{ }^{\prime \prime} 25$ \\
\hline Nikolaev & $\mathrm{p}$ & photo & 1961-1998 & 440 & $0 .{ }^{\prime \prime} 2$ \\
\hline Flagstaff & $\mathrm{p}, \mathrm{s} 3,4$ & $\mathrm{CCD}$ & $1995-2003$ & 2324 & $0 . \prime 2$ \\
\hline Mountain & $\mathrm{p}, \mathrm{s} 3,4$ & CCD & $1998-2003$ & 174 & $0 . .15$ \\
\hline VLA,ring occ. & $\mathrm{p}$ & radio & $1977-1985$ & 16 & $0 .{ }^{\prime \prime} 03-0.2$ \\
\hline \multicolumn{6}{|c|}{ NEPTUNE } \\
\hline USNO & $\mathrm{p}$ & transit & $1913-1993$ & 3804 & $0 .{ }^{\prime \prime} 5$ \\
\hline Tokyo & $\mathrm{p}$ & ph-e transit & $1963-1988$ & 320 & $0 . .5-0 .{ }^{\prime \prime} 8$ \\
\hline Bordeaux & $\mathrm{p}$ & ph-e transit & $1985-1993$ & 366 & 0.25 \\
\hline Bordeaux & $\mathrm{p}$ & $\mathrm{CCD}$ & 1997 & 28 & $0 . .2$ \\
\hline La Palma & $\mathrm{p}$ & ph-e transit & $1984-1998$ & 2212 & 0.25 \\
\hline Nikolaev & $\mathrm{p}$ & photo & 1961-1998 & 436 & $0 .{ }^{\prime \prime} 2$ \\
\hline Flagstaff & $\mathrm{p}, \mathrm{s} 1$ & $\mathrm{CCD}$ & $1995-2003$ & 1888 & 0.2 \\
\hline Mountain & $\mathrm{p}, \mathrm{s} 1$ & CCD & $1998-2003$ & 120 & 0.15 \\
\hline VLA,ring occ. & $\mathrm{p}$ & radio & 1981-1997 & 22 & $0 .{ }^{\prime \prime} 03-0 .{ }^{\prime \prime} 2$ \\
\hline
\end{tabular}

between EPM2004 and the ICRF have been obtained (in mas):

$$
\varepsilon_{x}=1.9 \pm 0.1, \varepsilon_{y}=-0.5 \pm 0.2, \varepsilon_{z}=-1.5 \pm 0.1,
$$

which are close to the rotation angles between DE405 and DE410. 
Table 3. Optical and radio observations used in the ephemeris solutions of the outer planets. (continued)

PLUTO

\begin{tabular}{|c|c|c|c|c|c|}
\hline $\begin{array}{l}\text { station, } \\
\text { object }\end{array}$ & $\begin{array}{l}\text { planet } \\
\text { satellite }\end{array}$ & type & $\begin{array}{c}\text { time } \\
\text { interval }\end{array}$ & $\begin{array}{l}\text { number } \\
\text { of obs. }\end{array}$ & $\begin{array}{l}\text { a priori } \\
\text { accuracy }\end{array}$ \\
\hline Different stat. & $\mathrm{p}$ & photo & 1914-1967 & 1164 & $0^{\prime \prime} 5-1^{\prime \prime}$ \\
\hline Different stat. & $\mathrm{p}$ & photo & 1969-1988 & 674 & $0^{\prime \prime} 5-1^{\prime \prime}$ \\
\hline Different stat. & $\mathrm{p}$ & photo & 1989-1995 & 82 & $0^{\prime \prime} 5-1^{\prime \prime}$ \\
\hline Pulkovo & $\mathrm{p}$ & photo & 1930-1993 & 416 & $0 . .5$ \\
\hline Tokyo & $\mathrm{p}$ & photo & 1994 & 24 & $0 .{ }^{\prime \prime} 3$ \\
\hline Bordeaux & $\mathrm{p}$ & ph-e transit & 1996 & 12 & $0 .{ }^{\prime \prime} 3$ \\
\hline Bordeaux & $\mathrm{p}$ & CCD & 1995-1997 & 64 & $0 . .2$ \\
\hline La Palma & $\mathrm{p}$ & ph-e transit & 1986-1998 & 760 & $0 . \prime 25$ \\
\hline Flagstaff & $\mathrm{p}$ & $\mathrm{CCD}$ & 1995-2003 & 1152 & $0 . .2$ \\
\hline Mountain & $\mathrm{p}$ & CCD & $2000-2003$ & 68 & $0 . \prime 15$ \\
\hline
\end{tabular}

Table 4. The formal standard deviations of elements of the planets

\begin{tabular}{lllrrrr}
\hline planet & $\begin{array}{c}a \\
{[\mathrm{~m}]}\end{array}$ & $\begin{array}{l}\sin i \cos \Omega \\
{[\mathrm{mas}]}\end{array}$ & $\begin{array}{r}\sin i \sin \Omega \\
{[\mathrm{mas}]}\end{array}$ & $\begin{array}{r}e \cos \pi \\
{[\mathrm{mas}]}\end{array}$ & $\begin{array}{r}e \sin \pi \\
{[\mathrm{mas}]}\end{array}$ & $\begin{array}{r}\lambda \\
{[\mathrm{mas}]}\end{array}$ \\
\hline Mercury & 0.105 & 1.654 & 1.525 & 0.123 & 0.099 & 0.375 \\
Venus & 0.329 & 0.567 & 0.567 & 0.041 & 0.043 & 0.187 \\
Earth & 0.146 & - & - & 0.001 & 0.001 & - \\
Mars & 0.657 & 0.003 & 0.004 & 0.001 & 0.001 & 0.003 \\
Jupiter & 639 & 2.410 & 2.207 & 1.280 & 1.170 & 1.109 \\
Saturn & 4222 & 3.237 & 4.085 & 3.858 & 2.975 & 3.474 \\
Uranus & 38484 & 4.072 & 6.143 & 4.896 & 3.361 & 8.818 \\
Neptune & 478532 & 4.214 & 8.600 & 14.066 & 18.687 & 35.163 \\
Pluto & 3463309 & 6.899 & 14.940 & 82.888 & 36.700 & 79.089 \\
& & & & & & \\
\hline
\end{tabular}

Table 5. The parameters of the Mars rotation.

\begin{tabular}{rcccr}
\hline$\dot{V}\left[^{o} /\right.$ day $]$ & $I_{q}\left[^{o}\right]$ & $\dot{I}_{q}\left[^{\prime \prime} /\right.$ year $]$ & $\Omega_{q}\left[^{o}\right]$ & $\dot{\Omega}_{q}\left[^{\prime \prime} /\right.$ year $]$ \\
\hline 350.891985294 & 25.1893930 & -0.0002 & 35.437685 & -7.5844 \\
\pm 0.000000012 & \pm 0.0000053 & \pm 0.0007 & \pm 0.000021 & \pm 0.0015 \\
\hline
\end{tabular}

\section{Results obtained}

The formal standard deviations of the orbital elements of planets are shown in the Table 4 , where $a$ - the semi-major axis, $i$ - the inclination of the orbit, $\Omega$ - the ascending node, $e$ - the eccentricity, $\pi$ - the longitude of perihelion, $\lambda$ - the mean longitude. Note that the uncertainties, given in this paper, are formal standard deviations; realistic error bounds may be an order of magnitude larger.

Accurate radar observations of planets and spacecraft have made it possible not only to improve the orbital elements of planets but to determine a broad set of astronomical constants as well: AU, parameters of Mars' rotation including its precessional rate, the masses of Ceres, Pallas, Vesta, Iris, Bamberga, Juno; the estimation of the total mass of the main asteroid belt, parameters of the $\operatorname{PPN}$ formalism $(\beta, \gamma)$, the variability of the gravitational constant $\mathrm{G}$, the solar quadrupole moment. Values for them are in Tables 5, 6 and 7. 
Table 6. Masses of Ceres, Pallas, Juno, Vesta, Iris, Bamberga in $\left(\mathrm{GM}_{i} / \mathrm{GM}_{\odot}\right) \cdot 10^{-10}$.

\begin{tabular}{rrrrrc}
\hline (1)Ceres & (2)Pallas & (3)Juno & (4)Vesta & (7)Iris & (324)Bamberga \\
\hline 4.753 & 1.027 & 0.151 & 1.344 & 0.063 & 0.055 \\
\pm 0.007 & \pm 0.003 & \pm 0.003 & \pm 0.001 & \pm 0.001 & \pm 0.001 \\
\hline
\end{tabular}

Table 7. The solar quadrupole moment, the radius and the mass of the asteroid ring, the total mass of the main asteroid belt.

\begin{tabular}{rrrr}
\hline $\mathrm{J}_{2}$ & $\mathrm{R}_{\text {ring }}$ & $\mathrm{M}_{\text {ring }}$ & $\mathrm{M}_{\text {belt }}$ \\
$10^{-7}$ & $\mathrm{AU}$ & $10^{-10} \mathrm{M}_{\odot}$ & $10^{-10} \mathrm{M}_{\odot}$ \\
\hline $1.9 \pm 0.3$ & $3.13 \pm 0.05$ & $3.35 \pm 0.35$ & $15.0 \pm 2.0$ \\
\hline
\end{tabular}

Table 8. Progress in the determination of the parameters of PPN formalism and $\dot{G} / G$.

\begin{tabular}{cccc}
\hline year & $\beta$ & $\gamma$ & $\dot{G} / G\left(10^{-11} \mathrm{yr}^{-1}\right)$ \\
\hline 1985 & $0.76 \pm 0.12$ & $0.87 \pm 0.06$ & $4.1 \pm 0.8$ \\
1994 & $1.014 \pm 0.070$ & $1.006 \pm 0.037$ & $0.28 \pm 0.32$ \\
2004 & $1.0000 \pm 0.0001$ & $0.9999 \pm 0.0001$ & $0.001 \pm 0.005$ \\
\hline
\end{tabular}

The value of the precession constant for Mars is close to the recent value obtained from Viking, Pathfinder landers and MGS radio tracking data (Yoder et al. 2003):

$$
\dot{\Omega}_{q}=\left[-7 .^{\prime \prime} 597 \pm 0 .{ }^{\prime \prime} 025(10 \sigma)\right] / \text { year. }
$$

Lately some papers have appeared where impossibility of a separate determination of PPN parameters and the solar oblateness from ranging observations is stated. However, the PPN parameters $(\beta, \gamma)$ and the solar oblateness cause secular and periodic effects among different planets and other orbital elements, therefore the estimations of the this parameters and possible variability of the gravitational constant have been simultaneously obtained.

Three main factors influence the progress in the improvement of parameters - reductions of the observational data, dynamical models of planet motion, and the observational data themselves. As an example, the progress in the determination of the AU (in $\mathrm{km}$ ) in Russia from ranging (Table 9), as well as in the estimation of parameters of PPN formalism and the time variation of the gravitation constant (Table 8) is given.

The last AU value of Table 9 differs from the value of the DE410 (Standish 2003) $149597870.6974 \pm 0.0003$ by $1.4 \mathrm{~m}$, which is the real error of the determination of the AU.

\section{Comparison DE410 and EPM2004}

The differences between various ephemerides are useful to know since they are indicative of the realistic accuracies of the ephemerides. Comparison between the latest versions of DE410 and EPM2004 over the time interval 1970-2010 has been made. These ephemerides are based on the similar data and the mathematical models, but distinguish by different way of taking into account asteroids, by their masses as well as corrections for the topography of planet surfaces and the solar corona.

Coordinates of Mercury and Venus have been obtained from fitting radar observations of these planets, having the uncertainties mainly about $\mathrm{km}$, so the maximum differences of geliocentric distances up to $258 \mathrm{~m}$ for Mercury and up to $139 \mathrm{~m}$ for Venus (Fig. 5) can be considered acceptable. 
Table 9. Progress in the determination of the AU (in $\mathrm{km}$ ) in Russia from ranging.

\begin{tabular}{lll}
\hline 149599300 & \pm 600 & Kotelnikov et al. 1962 \\
149597867.3 & \pm 0.3 & Akim et al. 1986 \\
149597870.62 & \pm 0.18 & Krasinsky et al. 1993 \\
$149597870.6960 \pm 0.0001$ & Pitjeva, 2004
\end{tabular}

The maximum differences of geliocentric distances for the Earth and the Mars are considerably less: up to $12.8 \mathrm{~m}$ for the Earth and up to $35.7 \mathrm{~m}$ for Mars, which is not surprising as data of MGS and Odyssey used have the uncertainties at the two-meter level. The differences may be explained by different account of asteroids and solar corona.

The availability of a number of spacecraft Jupiter data (besides optical observations) allow its ephemerides to be known better than those of other outer planets. The distance differences for Jupiter are less than $10 \mathrm{~km}$. For the other four outer planets the only observations are optical. Moreover, for Neptune and Pluto a single orbital period has not yet elapsed since the time when more or less accurate observations of these planets appeared. The distance differences amount for Saturn to $180 \mathrm{~km}$, for Uranus to $410 \mathrm{~km}$, for Neptune to $1200 \mathrm{~km}$, for Pluto to $14000 \mathrm{~km}$. Those are the current accuracies of the modern ephemerides.
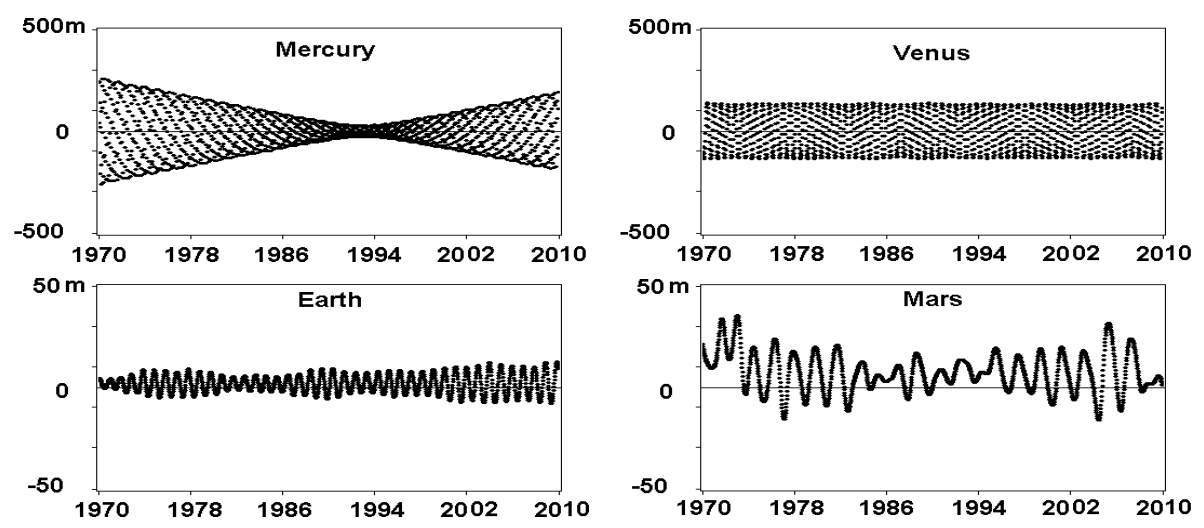

Figure 5. DE410-EPM2004: heliocentric distance differences for the inner planets, 1970-2010.

\section{References}

Akim, Eh. L., Brumberg, V. A., Kislik, M. D., Koljuka, Yu. F., Krasinsky, G. A., Pitjeva, E. V., Shiskov, V. A., Stepanianz, V. A., Sveshnikov, M. L. \& Tikhonov, V. F. 1986 In Proceedings of the IAU Symp. N 114, Relativity in Celestial Mechanics and Astrometry (ed. J. Kovalevsky \& V. A. Brumberg), Kluwer, Dordrecht, 63-68.

Bretagnon, P. \& Francou, G. 1988 A\&SA 202, 309-315.

Brumberg, V. A. 1972 Relativistic Celestial Mechanics. Izdatel'stvo "Nauka", Moskva, 382p. (in Russian)

Chapront, J. \& Chapront-Touzé, M. 1987 A\&A 190, 342-452.

Fienga, A. \& Simon, J.-L. $2004 A \mathscr{\xi} A$, in press.

Kotelnikov, V. A, \& Dubrovin, V. M., Kislik, M. D., Korenberg, E. B, Minashkin, B. P., Morozov, V. A., Nikitsky, N. I., Petrov, G. M., Rzhiga, O. N. \& Shachovskoy, A. M. 1962 Dokl. AN SSSR 145, 1035-1038. 
Krasinsky, G. A., Pitjeva, E.V., Sveshnikov, M. L. \& Chunajeva, L. I. 1993 Celest. Mech. 84 Dyn. Astr. 55, 1-23.

Krasinsky, G. A. \& Vasilyev, M. V. 1997 In Proceedings of the IAU Coll.165, Dynamics and Astrometry of Natural and Artificial Celestial Bodies (ed. I.M.Wytrzyszczak, J.H.Lieske, \& R.A.Feldman), Dordrecht, Kluwer, 239-244.

Krasinsky, G. A., Pitjeva, E. V., Vasilyev, M. V. \& Yagudina, E. I. 2002 Icarus 158, 98-105.

Krasinsky, G. A. 2002 Communication of IAA RAS 148, 27p.

Mignard, F. 2000 In Towards models and constants for sub-microarcsecond astrometry (ed. Johnston K. J., McCarthy D. D., Luzum B. J. \& Kaplan G. H.), U.S. Naval Observatory, Washington, DC, USA, 10-19.

Pitjeva, E. V. 2001 Celest. Mech. \& Dyn. Astr. 80, N 3/4, 249-271.

Standish, E. M. 1990 A $\mathscr{S} A$ 233, 252-271.

Standish, E. M. 1998 Interoffice Memorandum, 312.F-98-048, 18p.

Standish, E. M. 2003 Interoffice Memorandum, 312.N-03-009, 16p.

Standish, E. M. \& Fienga, A. 2002 A $8 A$ 384, 322-328.

Standish, E. M., Newhall XX, Williams, J. G. \& Folkner, W. M. 1995 Interoffice Memorandum 314.10-127, 22p.

Yoder, C. F., Konoplev, A. S., Yuan, D. N., Standish, E. M. \& Folkner, W.M. 2003 Science 300, Issue 5617, 299-303.

Williams, J. G. \& Dickey, J. O. 2002 In 13th International Workshop on Laser Ranging, 17p. Washington, D.C.

\section{Discussion}

Nicole Capitaine: Can you say for which kind of parameters the observations of transits of planets are useful?

Elena PitJeva: This observation may be used for the estimation of the variation of the solar radius. There are some examples where the variation of the solar radius has been estimated from transits.

JESus DE ALBA: Do you use your model to calculate the ephemeredes of potentially dangerous near-Earth objects?

Myles Standish: I will comment on that question: It would not be practical to use her model for that computation because the equations of motion are extremely complicated; it would terribly long to integrate. What you do is use her ephemeris after it is computed as perturbations on a different integration. 